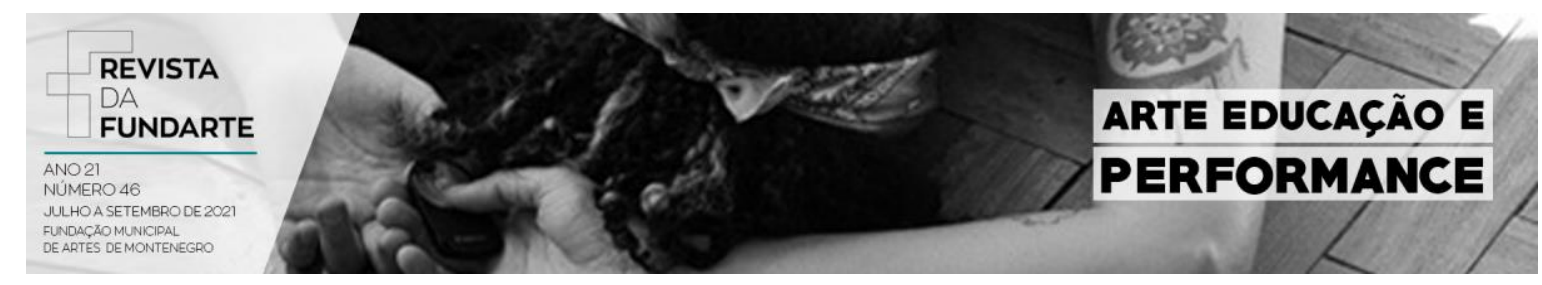

\title{
ARTE DIGITAL NA CIBERCULTURA: CONTEXTUALIZAÇÃO E DEBATES ATUAIS
}

\author{
Bianca Mörschbächer \\ Lúcia Bergamaschi Costa Weymar
}

DOI: http://dx.doi.org/10.19179\%2F2319-0868.908

MÖRSCHBÄCHER, Bianca; WEYMAR, Lúcia Bergamaschi Costa. Arte digital na cibercultura: contextualização e debates atuais. Revista da FUNDARTE. Montenegro, p.01-16, ano 21, no 46, setembro de 2021.

Disponível em: http://seer.fundarte.rs.gov.br/index.php/RevistadaFundarte/issue/archive $>30$ de setembro de 2021. 


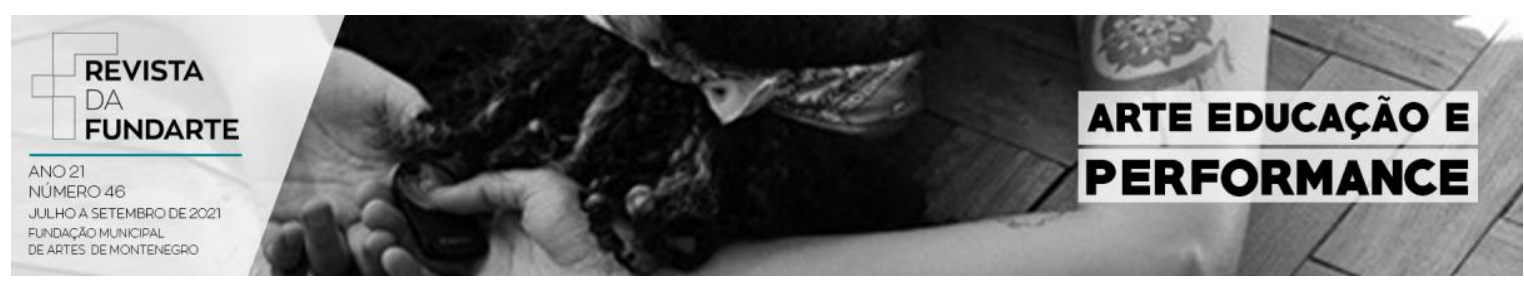

\title{
ARTE DIGITAL NA CIBERCULTURA: CONTEXTUALIZAÇÃO E DEBATES ATUAIS
}

\author{
Bianca Mörschbächer ${ }^{1}$ \\ Lúcia Bergamaschi Costa Weymar²
}

\begin{abstract}
Resumo: As tecnologias digitais estão cada vez mais presentes nas mais diversas áreas da sociedade, e na área das Artes não é diferente. Os modos de criação e expressão artística igualmente embarcam nestas mudanças tornando possíveis novos formas do fazer artístico em um ambiente virtual. Ao buscar melhor compreender o universo do desenho digital nos deparamos com diversas questões que o envolvem, como surgimento, funcionamento e contextos socioculturais do meio. O presente artigo representa um recorte de uma pesquisa maior vinculada ao Programa de Pós-Graduação em Artes Visuais da UFPEL, com apoio da CAPES, sobre o cenário no qual o desenho digital se insere no Curso de Graduação de Design Digital do Centro de Artes da citada universidade, cujo objetivo principal é relatar minha experiência com o tema enquanto estagiária docente.
\end{abstract}

Palavras-chave: Desenho Digital; Arte Digital; Arte e Tecnologia; Cibercultura.

\section{DIGITAL ART IN CYBERCULTURE: CONTEXTUALIZATION AND CURRENT DEBATES}

\begin{abstract}
Digital technologies are increasingly present in the most diverse areas of society, and in the area of the Arts it is no different. The modes of creation and artistic expression also embark on these changes, making possible new forms of artistic making in a virtual environment. In seeking to better understand the universe of digital drawing, we are faced with several issues that involve it, such as emergence, functioning and socio-cultural contexts of the environment. This article represents an
\end{abstract}

\footnotetext{
1 Mestranda do Programa de Pós-graduação em Artes Visuais da Universidade Federal de Pelotas com o apoio da bolsa CAPES. Graduada em Design Digital pela Universidade Federal de Pelotas. Artista digital e ilustradora freelancer.

2 Pós doutora pelo Núcleo de Design da Faculdade de Belas Artes da Universidade de Lisboa onde acaba de realizar a pesquisa "Lusitanidades: Design de Viagem, Viagem no Design, Brasil-Portugal" sob supervisão do professor Jorge dos Reis (ULISBOA, 2019). Doutora em Comunicação Social (PUCRS, 2010). Mestre em Educação (UFPEL, 2000). Graduada em Artes Plásticas (FURG, 1989). Professora do Mestrado em Artes Visuais do Centro de Artes (UFPEL) no qual ministra a disciplina D'autor, aproximações entre design e arte. Professora Associada dos Cursos de Design do Centro de Artes (UFPEL) e responsável pelas disciplinas Design de Identidade, Projeto de Cartaz e Design Autoral. Pesquisa temas ligados à autoria em design na pesquisa "(Des)autoria, design e arte". Idealizadora do "Suldesign Evento" em 1999; do "Suldesign Estúdio", em 2005, do Projeto de Extensão "Suldesign Galeria", em 2017. Responsável técnica e artística pela criação da Paralelo 31 , Revista Eletrônica do Programa de Pós Graduação em Artes Visuais (PPGAV, 2010). Atualmente coordena "7 artes que curam", projeto de extensão semanal na rede social Instagram nascido da crise pandêmica de 2020 .
}

MÖRSCHBÄCHER, Bianca; WEYMAR, Lúcia Bergamaschi Costa. Arte digital na cibercultura: contextualização e debates atuais. Revista da FUNDARTE. Montenegro, p.01-16, ano 21, oo 46, setembro de 2021.

Disponível em: http://seer.fundarte.rs.gov.br/index.php/RevistadaFundarte/issue/archive $>30$ de setembro de 2021. 


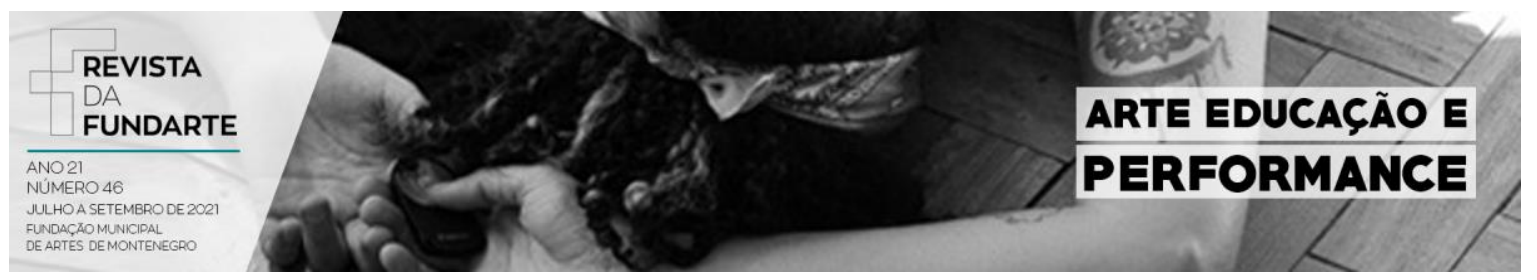

excerpt from a larger research linked to the Graduate Program in Visual Arts at UFPEL, with support from CAPES, about the scenario in which digital drawing is inserted in the Digital Design Graduate Course of the Arts Center of cited university, whose main objective is to report my experience with the subject as a teaching intern.

Keywords: Digital Drawing; Digital Art; Art and Technology; Cyberculture.

Reconheço no desenho um modo de expressão, representação e organização de ideias e sentimentos. Com o passar dos anos pude ter o privilégio de experimentar diferentes materiais, conhecer diferentes modos de criar e de me inspirar em diversos criadores. Vivenciei um processo de busca e aprendizado sobre arte que me permitiu traçar e visualizar diversos caminhos; dentre eles, o caminho do desenho digital. Nesta busca pelo conhecimento e pela experimentação artística me deparei com diversas questões transversais a este meio. Em certo momento compreendi que o desenho digital está atrelado a outros temas e áreas que me despertavam interesse. Interesse porque demarcam minha trajetória enquanto artista, ou seja, porque definem os contextos artísticos nos quais tenho me desenvolvido.

O contexto sobre o qual me aprofundo neste artigo é o da cibercultura face ao campo das artes. Após a iniciação no desenho tradicional ao longo da minha infância foi através da internet e das comunidades virtuais que me engajei em uma busca mais direcionada sobre as maneiras de melhorar meus desenhos, compartilhá-los com mais pessoas bem como acessar referências e obras de outros artistas. As comunidades artísticas na internet são um espaço de pertencimento, entretanto, foi somente ao iniciar a minha pesquisa de mestrado que compreendi a extensão da sua relevância para os artistas e, especialmente, para mim enquanto artista digital. A cibercultura, enquanto contexto da arte digital, influencia e é influenciada por ela; a arte digital se constrói junto à cibercultura e vice-versa. Portanto, é preciso reconhecer que a internet e as comunidades virtuais representam, hoje, importantes espaços de desenvolvimento, pertencimento, compartilhamento e engajamento de artistas e apreciadores de arte.

MÖRSCHBÄCHER, Bianca; WEYMAR, Lúcia Bergamaschi Costa. Arte digital na cibercultura: contextualização e debates atuais. Revista da FUNDARTE. Montenegro, p.01-16, ano 21, oㅡ 46, setembro de 2021.

Disponível em: http://seer.fundarte.rs.gov.br/index.php/RevistadaFundarte/issue/archive $>30$ de setembro de 2021. 


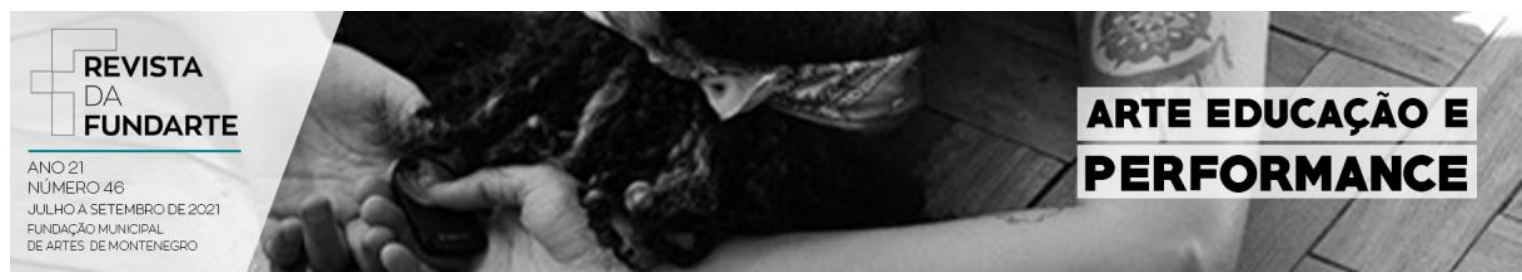

Este artigo representa um recorte de pesquisa de Mestrado em andamento no Programa de Pós-Graduação em Artes Visuais da Universidade Federal de Pelotas (UFPEL) que conta com o apoio de bolsa da Coordenação de Aperfeiçoamento de Pessoal de Nível Superior (CAPES). Tal pesquisa aborda o cenário da inserção do desenho digital no Curso de Design Digital do Centro de Artes da UFPel e tem como principal objetivo relatar minha experiência com 0 desenho digital enquanto estagiária docente em uma disciplina de desenho, naquela graduação. Importa declarar que o desenvolvimento pesquisa maior foi atravessado pelo recente contexto da pandemia da COVID-19. Portanto, aqui e agora, busco igualmente reconhecer o impacto deste contexto no campo das artes e da cibercultura uma vez que houve um repentino aumento na pressão sofrida pela sociedade para aderir ao uso constante das novas tecnologias de comunicação.

\section{A Revolução Digital no Contexto das Artes Plásticas}

A partir do final do século $X X$ a história da humanidade é marcada por um grande avanço tecnológico que se expande de forma exponencial e afeta seus mais diversos aspectos (GIDDENS, 2003; CASTELLS, 2008; LÉVY, 1999). Os impactos econômicos, políticos, sociais e culturais da nova realidade se aprofundam mais ainda a partir de processos de ampliação e democratização do acesso à internet.

Por um lado, a comunicação digital e o compartilhamento de informações facilitam a interação e a criação compartilhada. As novas ferramentas, aperfeiçoadas a cada dia, ampliam as possibilidades dos usuários e, ao mesmo tempo, não mais exigem deles conhecimento de desenvolvimento ou programação de softwares. As distâncias diminuem e a cultura e o conhecimento tornam-se cada vez menos territorializados e mais globalizados, uma vez que pessoas de diferentes regiões e países estão constantemente trocando informações em tempo real. A autora Lúcia Santaella (2003) comenta que a globalização não teria sido possível sem as

MÖRSCHBÄCHER, Bianca; WEYMAR, Lúcia Bergamaschi Costa. Arte digital na cibercultura: contextualização e debates atuais. Revista da FUNDARTE. Montenegro, p.01-16, ano 21, oㅡ 46, setembro de 2021.

Disponível em: http://seer.fundarte.rs.gov.br/index.php/RevistadaFundarte/issue/archive $>30$ de setembro de 2021. 


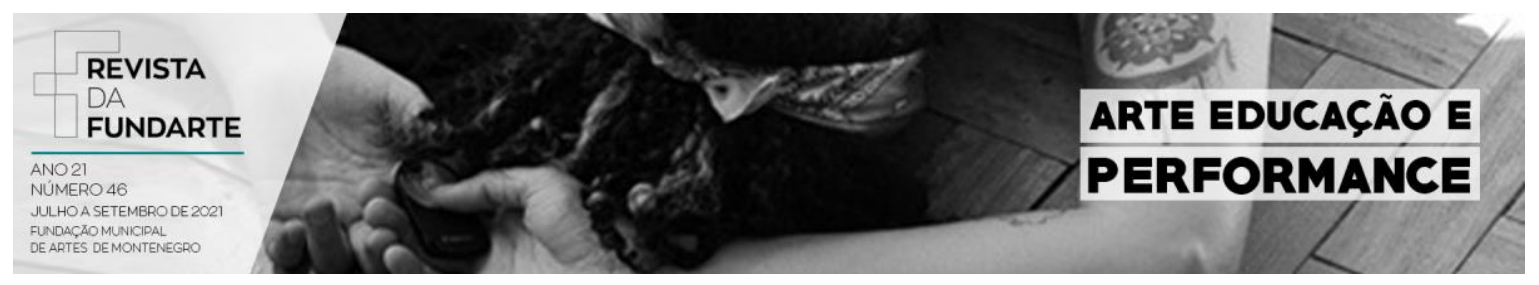

"poderosas tecnologias comunicacionais atuais". Ela ainda aponta para a importância e a grandiosidade dos impactos que estas tecnologias estão causando na sociedade, chamando este contexto de "revolução digital", permitindo que dados e informações cruzem oceanos e conectem diferentes partes do globo em questão de segundos em um ambiente virtual denominado "ciberespaço", um conceito muito bem desenvolvido por Pierre Lévy em seu livro "Cibercultura” (1999). Contudo, esta revolução digital se deu de forma bem acelerada através do âmbito da internet, onde "explodiu de maneira espontânea, caótica, superabundante" (SANTAELLA, 2003).

Neste contexto, de que modo a arte influencia e é influenciada pelo novo cenário de tecnologias digitais, isto é, pela cibercultura?

De fato, o acesso a obras - sejam históricas, contemporâneas, de renome ou anônimas - foi facilitado, o que permitiu que pessoas que não tinham condições físicas ou econômicas de frequentar museus, galerias e exposições ou, até mesmo, de adquirir quadros, livros, revistas e materiais impressos, possam, agora, apreciar tais obras por meio digital. E, igualmente, permitiu que, no caso dos artistas, expôlas com mais facilidade, com maior alcance e menor custo. Neste sentido, Lúcia Santaella (2009, p. 145) afirma que o processo de globalização "vem contribuindo grandemente para fortalecer o papel dos intermediários culturais, que administram as cadeias de distribuição das novas mídias globais", em especial após a consolidação da internet. Com isso, aumenta a capacidade de circulação de informações, incluindo estilos e obras de artes, desde as mais antigas e sagradas, até as produções mais atuais, por inúmeros lugares do mundo todo, e "tudo isso acaba por enfraquecer a autoridade iluminista das hierarquias ocidentais dominantes de alto gosto cultural".

Contudo, a "revolução" na arte pelo meio digital não se limita ao acesso e à exposição: desperta, igualmente, o interesse dos artistas quanto à criação. Se até o início dos anos 1960 as artes plásticas podiam ser compreendidas prioritariamente através da pintura e da escultura, logo a seguir passam a surgir novos movimentos

MÖRSCHBÄCHER, Bianca; WEYMAR, Lúcia Bergamaschi Costa. Arte digital na cibercultura: contextualização e debates atuais. Revista da FUNDARTE. Montenegro, p.01-16, ano 21, oㅡ 46, setembro de 2021.

Disponível em: http://seer.fundarte.rs.gov.br/index.php/RevistadaFundarte/issue/archive $>30$ de setembro de 2021. 


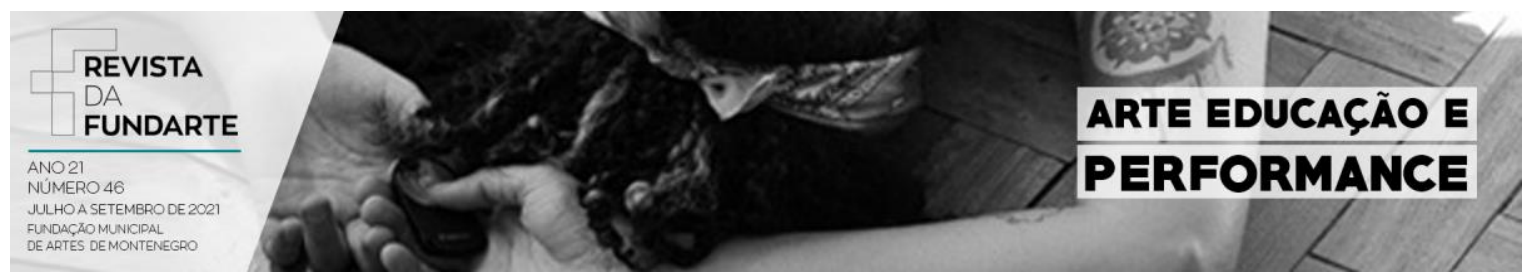

de artistas interessados em quebrar esta concepção tradicional de arte ao buscar diferentes suportes para a criação e expressão, e o foco passa a estar na comunicação e na reflexão (ARCHER, 2001). Ao mesmo tempo, na proximidade dos anos 1980, tornam-se cada vez mais populares os computadores para uso corporativo e pessoal, o que permite que diversos artistas passem, então, a eles ter acesso e, então, a experimentar diferentes possibilidades de criação.

\section{Conceituação da Arte Digital}

Segundo Santaella (2015), com o acesso às tecnologias dos computadores e aos programas de produção e manipulação de imagem e texto, diversos artistas se interessaram e passaram a fazer uso delas em suas produções. Essas produções, denominadas inicialmente "arte computacional", possuem ampla variedade de ferramentas, possibilidades e formatos, como gráfica, animação, escultura tridimensional, show de luzes controladas, eventos cinéticos e tele comunicacionais. Todos computadorizados.

Conforme a tecnologia avança, a arte digital se desenvolve, conjuntamente, inicialmente, a partir dos anos 1950, sendo dependente dos recursos que a tecnologia tinha a oferecer até então e, ao passo em que torna-se mais popular, resulta no investimento e no desenvolvimento de softwares cada vez mais específicos para processos artísticos. Os hardwares se desenvolvem, conjuntamente, neste processo através do avanço tecnológico de dispositivos periféricos como as mesas digitalizadoras as quais possuem o objetivo de simular o traço à mão no meio digital. Essas ferramentas acabam por tornar o computador uma extensão do ateliê, e um novo meio e suporte no qual o artista pode atuar.

A arte digital, de modo geral, pode ser compreendida como uma arte desenvolvida inteira ou parcialmente através de mídias digitais. Enquanto Santaella (2003, p. 153) define que "a arte tecnológica se dá quando o artista produz sua obra

MÖRSCHBÄCHER, Bianca; WEYMAR, Lúcia Bergamaschi Costa. Arte digital na cibercultura: contextualização e debates atuais. Revista da FUNDARTE. Montenegro, p.01-16, ano 21, oㅡ 46, setembro de 2021.

Disponível em: http://seer.fundarte.rs.gov.br/index.php/RevistadaFundarte/issue/archive $>30$ de setembro de 2021. 


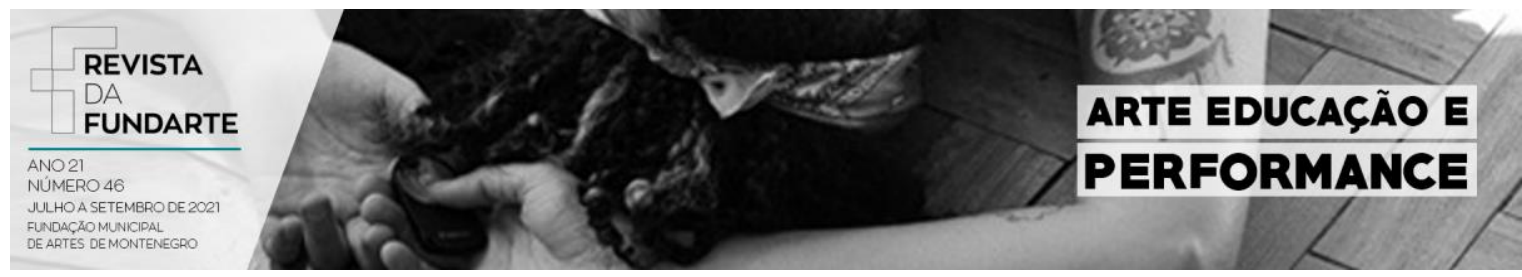

através da mediação de dispositivos maquínicos", Priscila Arantes (2005) opta por utilizar a expressão "arte em mídias digitais" por compreender que estes modos de expressão artística

[...] se apropriam de recursos tecnológicos desenvolvidos pelas indústrias eletrônico-informáticas e que disponibilizam interfaces áudio-tátil-motovisuais propícias para o desenvolvimento de trabalhos artísticos, seja no campo das artes baseadas em rede (online e wireless), seja na aplicação de recursos de hardware e software para geração de propostas estéticas offline. (ARANTES, 2005, p. 24-25).

Neste sentido, reconhecendo que o ambiente tecnológico atualmente permite o contato com diversos formatos de mídia (texto, imagem, áudio, vídeo, objetos tridimensionais, códigos, etc.) bem como a combinação de vários deles, acabam surgindo diversas vertentes dentro deste grande campo que é o da arte digital.

Portanto, a arte digital pode ser compreendida como um espaço plural, constituído, segundo Luís Silva (2004, p. 55), como "um amplo conjunto de obras e práticas artísticas e ao qual não corresponde uma estética unificada". O autor afirma ainda que ela assume um papel referencial na produção artística atual ao "condensar em si própria um conjunto de questões, de temáticas, características da contemporaneidade". Contudo, destaca-se que a sua popularidade e disseminação ainda não se refletem em representatividade equivalente nos espaços institucionais de legitimação.

\section{Comunidades Artísticas na Cibercultura}

Um ponto muito importante e que merece destaque, é de que a arte digital se constrói e se consolida a partir do próprio meio em que nasce e é amplamente pesquisada, exercitada e desenvolvida através da colaboratividade encontrada nas comunidades artísticas presentes na internet. Assim, é possível perceber que a configuração deste meio é diferente daqueles meios tradicionais o que leva à necessidade de ser abordada e estudada a partir de outra perspectiva, pois segundo

MÖRSCHBÄCHER, Bianca; WEYMAR, Lúcia Bergamaschi Costa. Arte digital na cibercultura: contextualização e debates atuais. Revista da FUNDARTE. Montenegro, p.01-16, ano 21, ํo 46, setembro de 2021.

Disponível em: http://seer.fundarte.rs.gov.br/index.php/RevistadaFundarte/issue/archive $>30$ de setembro de 2021. 


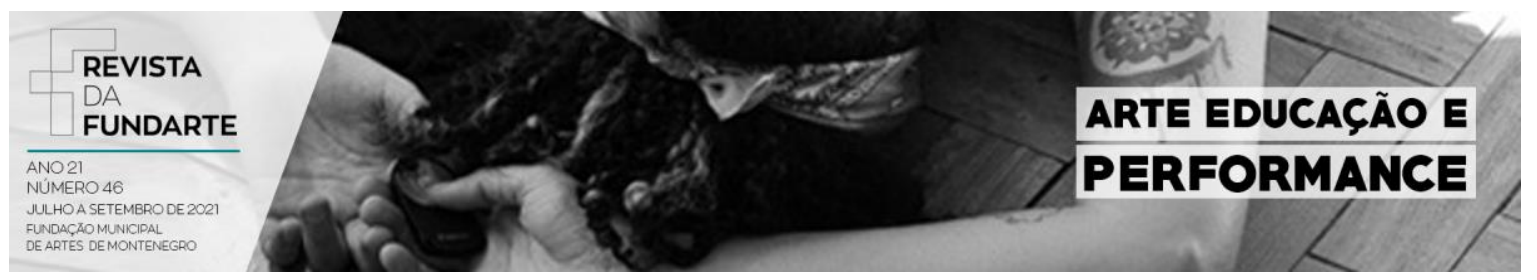

Débora Gasparetto "cada núcleo artístico dialoga com o espaço-tempo onde atua, com a cultura na qual está inserido, estabelecendo seus próprios mecanismos e estruturas de atuação" (GASPARETTO, 2013, P. 1900).

A arte digital nasce a partir dos anos 1990, trazendo uma série de especificidades. As estruturas, os profissionais e os mecanismos de legitimação do sistema da arte contemporânea precisam ser reavaliados, "reeducados" e direcionados para um novo momento, atrelado às mídias digitais, porém suas especificidades são tamanhas que parece requerer um contexto mais específico. (GASPARETTO, 2013, p. 1905).

Neste texto Gasparetto acaba por se referir à "cultura digital", a qual conhecemos como cibercultura, cuja definição está atrelada, conforme Pierre Lévy (1999), à definição de ciberespaço, que também pode ser lido como "rede", ou seja, [...] o espaço de comunicação, aberto pela interconexão mundial dos computadores e das memórias dos computadores. (p. 17).

Nesse sentido, a cibercultura pode ser definida como "o conjunto de técnicas (materiais e intelectuais), de práticas, de atitudes, de modos de pensamento e de valores que se desenvolvem juntamente com o crescimento do ciberespaço" (LÉVY, 1999, p. 14). Esta definição, no entanto, levanta a problemática compartilhada pelas diversas áreas do conhecimento ao abordar a internet: A cibercultura tem possibilitado a emancipação ou a dominação social? Levy não apresenta uma resposta ao dilema, no entanto, reconhece na cibercultura características específicas que lhe são próprias e a difere de sistemas anteriores como, principalmente, seu conceito aberto, de mudança constante e acelerada e, portanto, imprevisível.

No entanto, aqui nos limitaremos a pensar a cibercultura relacionada às comunidades artísticas nela presentes. Desde a época da minha graduação tenho refletido sobre como se dá a formação do artista digital e, tomando como referência minha trajetória enquanto artista-pesquisadora, percebo a importância da internet neste contexto, pois, atualmente, é através dela que muitos artistas têm acesso a

MÖRSCHBÄCHER, Bianca; WEYMAR, Lúcia Bergamaschi Costa. Arte digital na cibercultura: contextualização e debates atuais. Revista da FUNDARTE. Montenegro, p.01-16, ano 21, oㅡ 46, setembro de 2021.

Disponível em: http://seer.fundarte.rs.gov.br/index.php/RevistadaFundarte/issue/archive $>30$ de setembro de 2021. 


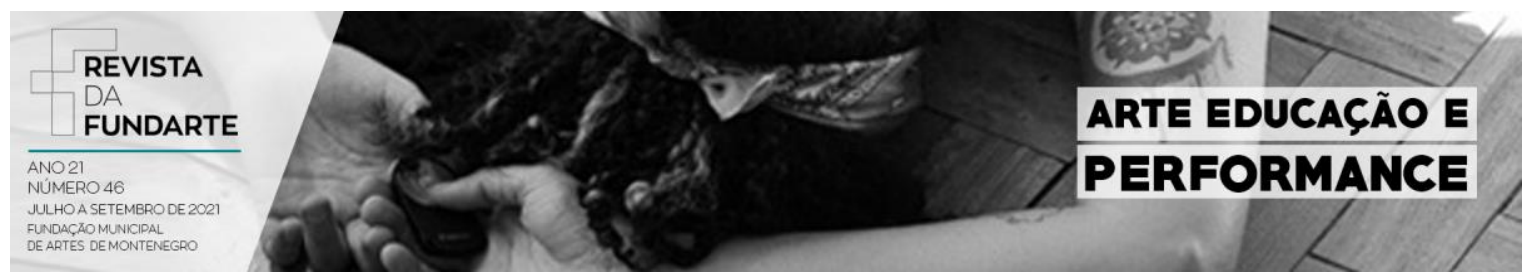

conteúdos que servem de aporte para suas produções. É no meio digital, também, que se tem contato com demais pessoas interessadas pelos mesmos assuntos, formando, assim, redes de contatos profissionais e informais. Tal ambiente digital abarca sites, blogs, redes sociais, grupos e fóruns, os quais possibilitam a realização de trocas de conhecimentos, conteúdos, opiniões, etc.

$\mathrm{Na}$ internet, os artistas buscam fazer parte de grupos onde as pessoas divulgam o que (e o como) estão produzindo, o que os faz se sentirem mais motivados a aprender um pouco mais. É algo colaborativo. O artista se sente pertencente, pois sempre terá alguém que vai saber um pouco menos e alguém que vai saber um pouco mais sobre o assunto; sente-se, então, à vontade para divulgar suas próprias produções e modos de fazer algo. Desta maneira, o processo de busca por descobrir seu próprio traço, os modos de como se identifica e se expressa no desenho e nos demais materiais desenvolvidos no design, torna-se mais presente. Mesmo quando uma peça é desenvolvida puramente para publicidade ainda há diferentes modos de fazer isso, as quais são guiadas por diferentes modos de expressão e diferentes propósitos e nichos do público-alvo.

É interessante pensar tais plataformas virtuais, que contemplam e abrigam produções em artes visuais, enquanto ambiente virtual de troca entre artistas conectando-os a partir de diversos locais do mundo. A pesquisadora Diana Domingues (1997) aborda este tópico ao relatar que por meio da internet ocorrem encontros e interações a distância, o que acaba por favorecer o surgimento de grupos e comunidades virtuais baseadas em interesses em comum. Ou seja, "o corpo assume a capacidade de circular no planeta, entrando em zonas privadas de intimidade de casas, conecta-se numa rede mundial”. (DOMINGUES, 1997 p. 21)

O ambiente virtual acaba por ser percebido enquanto um espaço rico em possibilidades de criação e reflexão, isto é, enquanto um grande ateliê que abraça as necessidades dos artistas contemporâneos que não somente desenvolvem seus procedimentos técnicos como também produzem pensamentos estéticos, sociais e

MÖRSCHBÄCHER, Bianca; WEYMAR, Lúcia Bergamaschi Costa. Arte digital na cibercultura: contextualização e debates atuais. Revista da FUNDARTE. Montenegro, p.01-16, ano 21, ํo 46, setembro de 2021.

Disponível em: http://seer.fundarte.rs.gov.br/index.php/RevistadaFundarte/issue/archive $>30$ de setembro de 2021. 


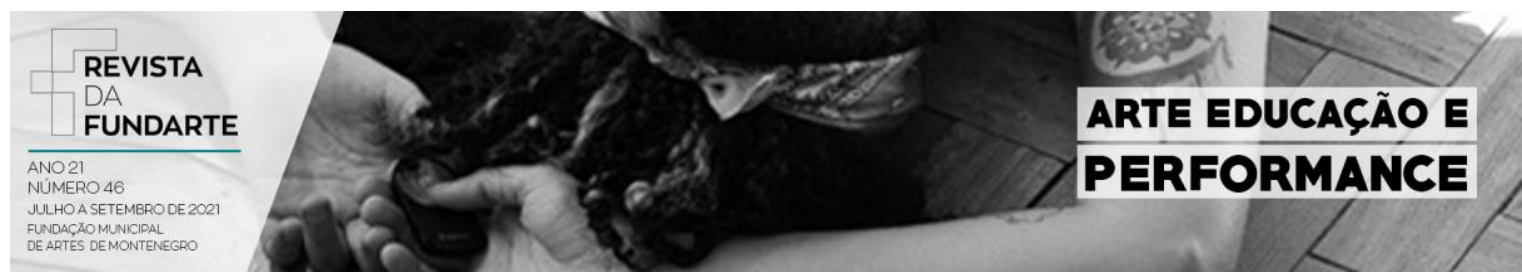

culturais a respeito da relação da sua arte com o século em que vivem. Neste contexto, proponho o uso do termo "ateliê digital", o qual pode ser entendido como um espaço de estudo, produção, reflexão e troca entre demais artistas, tal como um ateliê físico, porém, no ciberespaço. Lévy (1999) defende que a interconexão é a base do desenvolvimento de comunidades virtuais, as quais se estabelecem a partir de afinidades de interesses, conhecimentos ou projetos conjuntos através de um processo de colaboração e troca. O autor ainda reforça que "longe de serem frias, as relações on-line não excluem as emoções fortes" (LÉVY, 1999. p. 128).

As comunidades virtuais se encontram através de redes sociais e, dentre os artistas que junto a elas crescem, compartilhando e criando conhecimento em conjunto, surgem grandes nomes na área, hoje referências e inspirações, cujas produções se tornaram amplamente reconhecidas no meio artístico digital contemporâneo.

Interações entre artistas, artes e público funcionam de maneira mais horizontal nos meios informais e é possível acessar grandes nomes e suas produções a partir de seus perfis em redes sociais. Tal dinâmica dá-se diferentemente em comparação ao campo artístico tradicional no qual é mais difícil acessar um artista e suas obras ainda que os novos recursos digitais tenham ampliado, igualmente, a possibilidade de acesso a outros tipos de arte, a exemplo das visitas virtuais em museus. O campo da arte digital é uma linguagem artística recente na qual se faz necessário um novo viés de pensamento.

Conteúdos referentes a inúmeros estilos artísticos são amplamente encontrados na internet através de páginas, grupos, fóruns e perfis em redes sociais criados pelos artistas que interagem entre si. A interação e o compartilhamento online marcam outro ponto importante ao se debater arte digital que é a nova configuração da comunidade artística e sua relação com os demais públicos. Neste sentido, Domingues (1997) afirma que

MÖRSCHBÄCHER, Bianca; WEYMAR, Lúcia Bergamaschi Costa. Arte digital na cibercultura: contextualização e debates atuais. Revista da FUNDARTE. Montenegro, p.01-16, ano 21, oㅡ 46, setembro de 2021.

Disponível em: http://seer.fundarte.rs.gov.br/index.php/RevistadaFundarte/issue/archive $>30$ de setembro de 2021. 


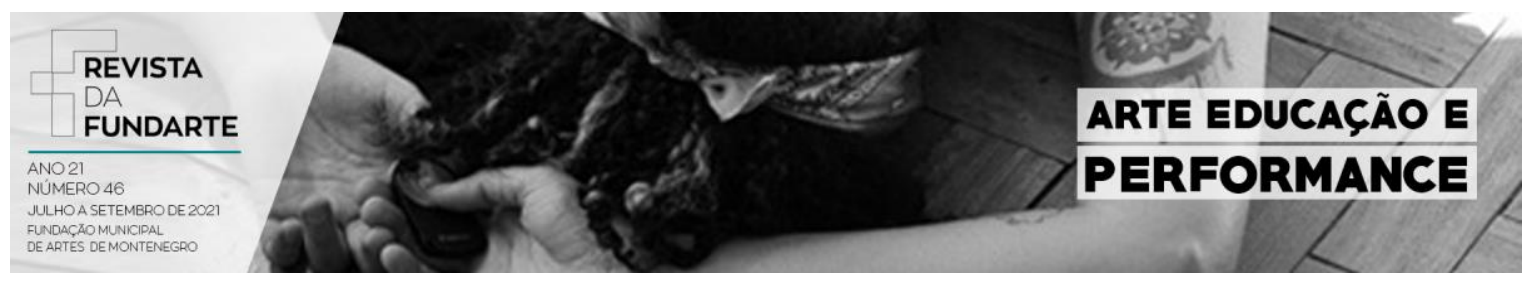

\begin{abstract}
A forma mais conhecida de circulação da arte na rede está sendo permitida pela Internet que faz proliferar os websites artísticos, muitos deles com possibilidades de interação. Nessa perspectiva se colocam os netmuseus, as netgalerias, os netmagazines que disseminam informações sobre arte. [...] As comunicações que se fazem na Net demandam um pensamento associativo, não-linear, explorando estruturas manipuláveis, através de links que permitem abrir e fechar janelas no ciberespaço. (DOMINGUES, 1997, p.20-21).
\end{abstract}

É importante destacar o espaço cada vez maior da arte no meio digital dado por netmuseus, netgalerias e netmagazines, acima mencionados, bem como pelas comunidades virtuais. Várias iniciativas têm sido estimuladas nos últimos anos, sobretudo a partir da crise sanitária mundial surgida no início de 2020.

\title{
O Contexto da Pandemia causada pela COVID-19
}

O cenário trágico e atípico na história mundial impactou nossas concepções e modos de atuar em diversas áreas de nossas vidas, seja no âmbito pessoal ou coletivo. Para Boaventura de Sousa Santos (2020, p. 29), em seu recente livro "A cruel pedagogia do vírus",

\begin{abstract}
A pandemia e a quarentena estão a revelar que são possíveis alternativas, que as sociedades se adaptam a novos modos de viver quando tal é necessário e sentido como correspondendo ao bem comum. Esta situação torna-se propícia a que se pense em alternativas ao modo de viver, de produzir, de consumir e de conviver nestes primeiros anos do século XXI.
\end{abstract}

Com o contexto de globalização, especialistas de diversas áreas já previam mudanças nos espaços de educação, trabalho, lazer, dentre outros, para as próximas décadas. Porém, algumas dessas mudanças foram colocadas, repentinamente, na ordem do dia, acelerando processos e impossibilitando tratar parte destes enquanto uma escolha a ser realizada. $O$ trabalho remoto, a educação remota e à distância, e a comunicação virtual chegaram como uma realidade posta,

MÖRSCHBÄCHER, Bianca; WEYMAR, Lúcia Bergamaschi Costa. Arte digital na cibercultura: contextualização e debates atuais. Revista da FUNDARTE. Montenegro, p.01-16, ano 21, no 46, setembro de 2021.

Disponível em: http://seer.fundarte.rs.gov.br/index.php/RevistadaFundarte/issue/archive $>30$ de setembro de 2021. 


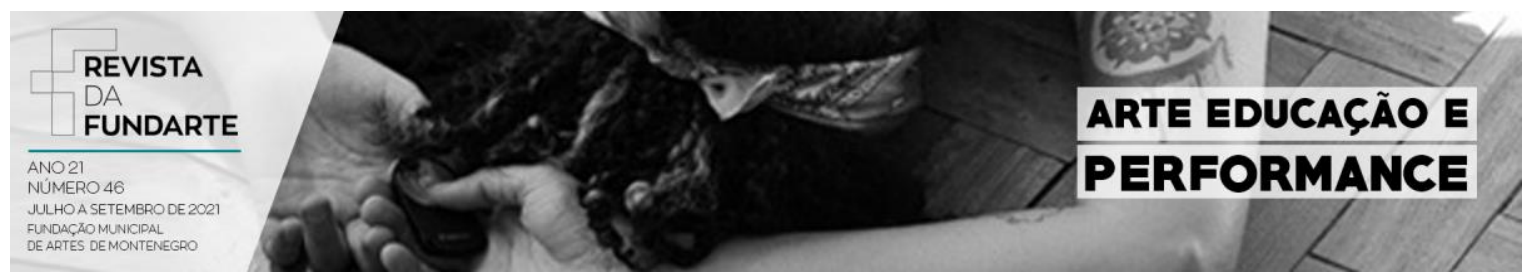

indiscutível, inserida no contexto digital. A partir de então foi necessário, até mesmo exigida, nossa reinvenção pessoal e profissional.

Passamos a utilizar espaços virtuais e as novas tecnologias para nos comunicarmos e nos integrarmos à sociedade, suprindo em parte nossas necessidades. Descobrimos inúmeros aplicativos, e surgiram tantos outros, para encontros, reuniões, aulas e lives. Ademais, passamos a nos entender como "teletrabalhadores, telealunos, youtubers, editores e produtores de vídeo da noite para o dia" (NASCIMENTO, 2020, p. 29).

No decorrer desses longos meses foram sendo buscadas e desenvolvidas novas estratégias para melhor lidarmos com os impactos psicológicos sofridos e, nesse contexto, as produções artísticas e de entretenimento têm se mostrado fundamentais.

O isolamento nos trouxe dias tensos. Frente ao medo da morte, da perda, do enfrentamento da crise financeira e das privações, a arte junto à tecnologia nos envolve em processos de entretenimento e distração, colaborando com um pouco de leveza aos nossos dias e auxiliando-nos a manter a saúde mental. (NASCIMENTO, 2020, p. 38).

De fato, as produções audiovisuais como filmes, séries, animações, jogos e até mesmo vídeos produzidos de modo amador se encontram em uma posição de destaque no âmbito do entretenimento e distração, sobretudo podendo ser acessadas com grande facilidade através da internet. Contudo, a maioria destas produções nos mantém apenas na posição de um espectador passivo mesmo sendo capazes de despertar emoções e gerar reflexões.

Surge, então, o fazer artístico como alternativa de expressão e compreensão dos mais diversos sentimentos e tensões causados pela pandemia e, consequentemente, pelo o isolamento social. Nascimento (2020) destaca a importância do papel da arte em "ajudar a lidar com o caos dos nossos pensamentos (por vezes destrutíveis, nesse período) e em nos auxiliar a aprender e demarcar

MÖRSCHBÄCHER, Bianca; WEYMAR, Lúcia Bergamaschi Costa. Arte digital na cibercultura: contextualização e debates atuais. Revista da FUNDARTE. Montenegro, p.01-16, ano 21, oㅡ 46, setembro de 2021.

Disponível em: http://seer.fundarte.rs.gov.br/index.php/RevistadaFundarte/issue/archive $>30$ de setembro de 2021. 


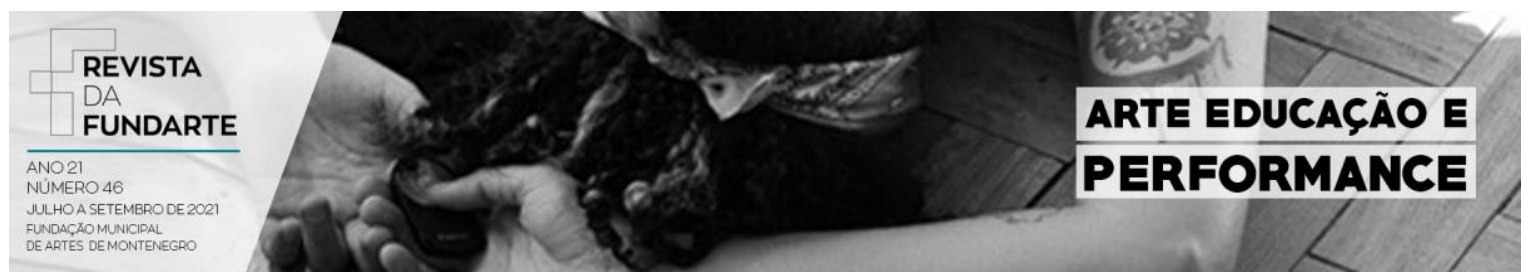

nossa identidade." (p.43), e ainda do papel dos artistas-educadores em se apropriarem de suas produções para se colocarem no mundo enquanto sujeitos questionadores, investigadores de si e do outro, que neste caso pode ser entendido como o cenário da doença. O autor ainda conclui compreendendo que este contexto pode ser visto como uma "oportunidade para redescobrirmos nossas potencialidades e natureza, nossa solidariedade, nosso senso de criatividade e resiliência" (NASCIMENTO 2020, p. 43).

Nas artes produzidas no/sobre o contexto da pandemia é possível perceber diferentes pontos de vista de uma mesma questão. São artes que relatam um novo cotidiano, que expõem nossos momentos de angústia, solidão e medo, nossos refúgios e também são artes que reconhecem e homenageiam aqueles que estão na linha de frente do combate à pandemia, e que denunciam e criticam os que negam a gravidade da situação.

Apesar da ausência de dados, devido ao recente contexto pandêmico, há fortes indícios para se acreditar que as comunidades artísticas já estabelecidas no ambiente digital tenham sofrido uma forte expansão. Com o isolamento social e o cancelamento de diversos tipos de atividades presenciais, o tempo em casa, para algumas pessoas, tem sido dedicado ao desenvolvimento de novas ou já existentes habilidades e/ou hobbies. Também, cresce a necessidade de busca por espaços de interação, pertencimento e acolhimento.

O desenvolvimento de comunidades virtuais se apoia na interconexão. Uma comunidade virtual é construída sobre as afinidades de interesses, de conhecimentos, sobre projetos mútuos, em um processo de cooperação ou de troca, tudo isso independentemente das proximidades geográficas e das filiações institucionais. [...] longe de serem frias, as relações on-line não excluem as emoções fortes. (LEVY, 1999, p. 128).

É preciso, ainda com mais urgência, romper com a resistência de compreender o espaço virtual como um espaço também real. Mesmo com as

MÖRSCHBÄCHER, Bianca; WEYMAR, Lúcia Bergamaschi Costa. Arte digital na cibercultura: contextualização e debates atuais. Revista da FUNDARTE. Montenegro, p.01-16, ano 21, oㅡ 46, setembro de 2021.

Disponível em: http://seer.fundarte.rs.gov.br/index.php/RevistadaFundarte/issue/archive $>30$ de setembro de 2021. 


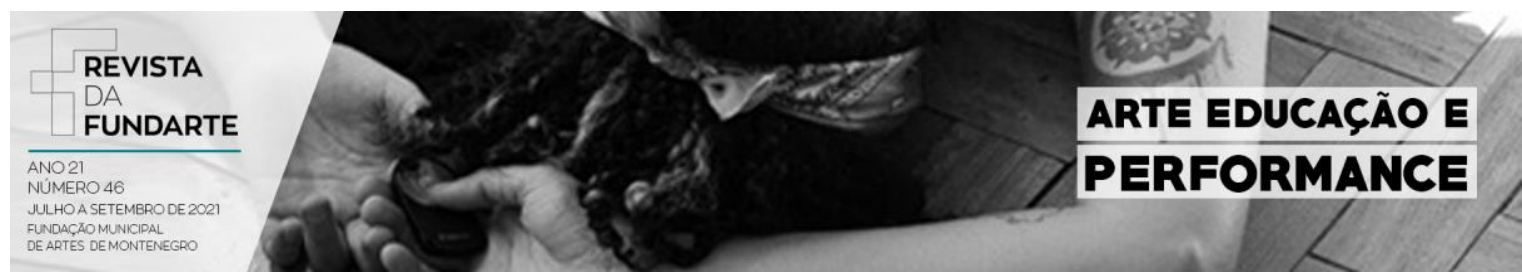

limitações e desafios encontrados já somos capazes de perceber que "afinidades, alianças intelectuais, até mesmo amizades podem desenvolver-se nos grupos de discussão, exatamente como entre pessoas que se encontram regularmente para conversar" (LÉVY, 1999, p. 128).

\section{Considerações Finais}

$\mathrm{Na}$ presente investigação acabo de abordar a relação entre sociedade e novas tecnologias no campo da arte, a fim de contextualizar temas e problemas que movem a minha pesquisa maior de pós-graduação e, também, considerando o contexto de pandemia causada pelo coronavírus. Ou seja, a reflexão a respeito dos temas e problemas mencionados, junto ao estudo preliminar da literatura da área, tem contribuído para o aprofundamento de questões nela levantadas tais como, relembrando, os espaços de ensino e de aprendizagem do desenho digital na universidade.

A pesquisa aponta que para investigar parte das relações entre arte e tecnologia nos tempos atuais é necessário compreender também o ambiente em que esta relação se dá e os fatores sociais que se estabelecem a partir disso, ou seja, os conceitos de ciberespaço e cibercultura. A partir daí as reflexões sobre arte digital, desenho digital e características que Ihe são próprias se tornam muito mais ricas, especialmente a partir do cenário de distanciamento social, onde todos os fatores mencionados se intensificam, uma vez que o uso da tecnologia tem sido uma boa alternativa para conectar virtualmente grupos e indivíduos.

Os debates apresentados reforçam a relevância do aprofundamento de estudos sobre arte e novas tecnologias, bem como suas potencialidades na educação frente aos desafios atuais relacionados a processos de ensino e aprendizagem.

MÖRSCHBÄCHER, Bianca; WEYMAR, Lúcia Bergamaschi Costa. Arte digital na cibercultura: contextualização e debates atuais. Revista da FUNDARTE. Montenegro, p.01-16, ano 21, oㅡ 46, setembro de 2021.

Disponível em: http://seer.fundarte.rs.gov.br/index.php/RevistadaFundarte/issue/archive $>30$ de setembro de 2021. 


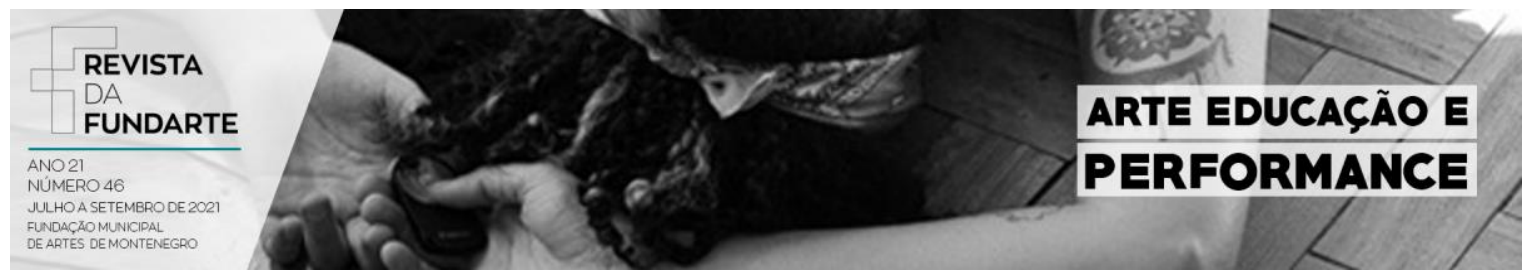

\section{Referências:}

ARANTES, Priscila. Arte e mídia: perspectivas da estética digital. Senac, 2005.

ARCHER, Michael. Arte contemporânea: uma história concisa. São Paulo: Martins fontes, 2001.

CASTELLS, Manuel. A Sociedade em rede. Volume I. Paz e Terra: São Paulo, 2008.

DOMINGUES, Diana. A Arte no Século XXI: A Humanização das Tecnologias. São Paulo: Unesp, 1997.

GASPARETTO, Débora Aita. A Arte Digital no Ecossistema da Arte. In: ANPAP - 22ํㅡㄴ Encontro Nacional de Pesquisadores em Artes Plásticas: Ecossistemas Estéticos 1. Ed. - 2013. p. 1898-1912. Disponível em: <http://www.anpap.org.br/anais/2013/ANAIS/simposi

os/01/Debora\%20Aita\%20Gasparetto.pdf> Acesso em: 21.09.2020.

GIDDENS, Anthony. Mundo em Descontrole: O Que a Globalização está Fazendo de Nós. 3 ed. Rio de Janeiro: Record, 2003.

LÉVY, Pierre. Cibercultura. trad. Carlos Irineu da Costa. São Paulo: Editora, v. 34, p. 260, 1999.

NASCIMENTO, Caroline Cavalcante. Educação em tempos de pandemia: O lugar do artista-docente. SCIAS-Arte/Educação, v. 7, n. 1, p. 25-44, 2020.

SANTAELLA, Lucia. As Comunicações e as Artes estão Convergindo?. Revista Farol, v. 1, n. 6, p. 20-44, 2015.

SANTAELLA, Lúcia. Da cultura das mídias à cibercultura: o advento do pós-humano. São Paulo: 2003.

SANTAELLA, Lucia. O Pluralismo Pós-Utópico da Arte. ARS, São Paulo, v. 7, n. 14, p. 130-151, 2009. Disponível em

<https://www.scielo.br/scielo.php?script=sci_arttext\&pid=S1678-

$53202009000200010>$. Acesso em 30 de maio 2019.

SANTOS, Boaventura de Sousa. A cruel pedagogia do vírus. Coimbra: Edições Almedina, S.A., 2020.

MÖRSCHBÄCHER, Bianca; WEYMAR, Lúcia Bergamaschi Costa. Arte digital na cibercultura: contextualização e debates atuais. Revista da FUNDARTE. Montenegro, p.01-16, ano 21, ํo 46, setembro de 2021.

Disponível em: http://seer.fundarte.rs.gov.br/index.php/RevistadaFundarte/issue/archive $>30$ de setembro de 2021. 


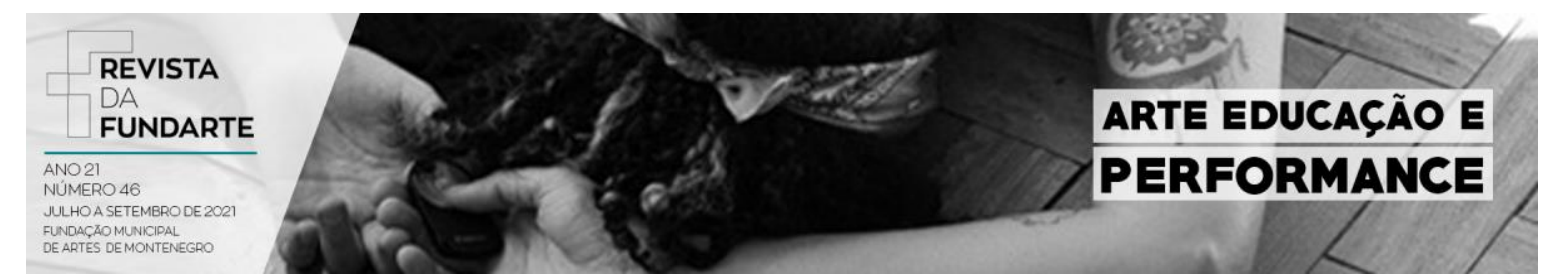

SILVA, Luís. Arte digital e mundos artísticos: Becker revisitado. In: Actas dos ateliers do Vo Congresso Português de Sociologia Sociedades Contemporâneas: Reflexividade e Ação Atelier: Artes e Culturas. 2004.

MÖRSCHBÄCHER, Bianca; WEYMAR, Lúcia Bergamaschi Costa. Arte digital na cibercultura: contextualização e debates atuais. Revista da FUNDARTE. Montenegro, p.01-16, ano 21, nํ 46, setembro de 2021.

Disponível em: http://seer.fundarte.rs.gov.br/index.php/RevistadaFundarte/issue/archive > 30 de setembro de 2021. 